\section{In Vitro Factors During Ovule Culture Affect Development and Conversion of Immature Peach and Nectarine Embryos}

\author{
David W. Ramming, Richard L. Emershad, and Carol Foster \\ U.S. Department of Agriculture, Agricultural Research Service, 9611 \\ S. Riverbend Avenue, Parlier, CA 93648
}

Additional index words. embryo rescue, Prunus, breeding, stone fruit

\begin{abstract}
Various in vitro conditions for culture of ovules prior to extraction and culture of immature embryos of peach [Prunus persica (L.) Batsch] and nectarine [Prunus persica (L.) Batsch var. nucipersica Schneid.] were investigated. Culture vessels consisting of test tubes, petri dishes, and polycarbonate jars were tested along with various types of support and nutrient media. Agar support was superior to liquid media with filter paper supports. Agar produced the largest embryos with $90 \%$ to $93 \%$ being converted into plants compared to liquid with only $1 \%$ to $12 \%$ embryo conversion. The best ovule orientation and support was with the micropyle down and pushed halfway into an agar-gelled medium. In experiments two and three, test tubes with vertical ovule orientation (micropyle end of ovule pushed into agar) produced larger embryos, the largest plants and the greatest percentage of embryos that converted into plants $(60 \%$ and $91 \%)$. Petri dish treatments were less successful in embryo conversion than test tubes and polycarbonate jars. The addition of activated charcoal (AC) to an agar-gelled medium produced significantly larger embryos with a similar conversion rate. The addition of an agar-gelled medium to culture vessels reduces preparation time compared to filter paper supports, and placing each ovule within a test tube eliminates cross contamination, making immature embryo culture more successful.
\end{abstract}

Seeds of peach and nectarine fruit that ripen in $<90 \mathrm{~d}$ are considered immature. During this period of rapid fruit enlargement and ripening, the embryos within these seeds have not had sufficient time to attain full size and mature physiologically. Embryo abortion usually occurs during the period of fruit softening. These seeds when planted in soil will not germinate; consequently early-ripening genotypes are limited for use as male parents in breeding programs. Therefore, when developing earlyripening progenies with conventional breeding methods, breeders have used only mid- to lateseason cultivars that develop mature seeds as female parents. When early-ripening genotypes are hybridized with mid- to late-season genotypes, only a small percentage of the hybrid population develops as early-ripening progeny, making the development of new cultivars slow and inefficient. Breeding efficiency can be increased when embryo culture is utilized, whereby both parents are early-ripening, resulting in greater percentages of hybrids that are as early or earlier than their parents.

Blake (1939) was the first peach breeder to utilize the embryo rescue technique developed by Tukey (1934). Ramming (1990), refining the embryo culture techniques developed by Smith et al. (1969), reported the advancement of progeny ripe dates by 10 to 38 d earlier than their parents. Plant development from embryos $>10 \mathrm{~mm}$ ranged from $57 \%$ to $93 \%$. However,

Received for publication 26 Oct. 2001. Accepted for publication 27 Aug. 2002. only $6 \%$ to $50 \%$ of embryos $<10 \mathrm{~mm}$ developed into plants on a modified Murashige and Skoog (1962) medium. Subsequently 98\% and $100 \%$ germination with $100 \%$ survival was obtained from peach and nectarine embryos 5 to $6 \mathrm{~mm}$ in length respectively, when cultured on Woody Plant medium (Emershad and Ramming, 1994).

Currently the earliest ripening peach and nectarine germplasm has embryo lengths measuring $<1 \mathrm{~mm}$ when the fruit are ripe. Embryo rescue techniques have been inadequate for development and germination of these embryos. Ramming (1985) utilized the cotton ovule culture technique reported by Stewart and Hsu $(1977,1978)$ to obtain plants from 1-mm embryos. This procedure utilizes a liquid medium with a filter paper support. Combining the above procedure with embryo culture allowed up to $35 \%$ conversion of embryos into plants (Ramming, 1990). In our efforts to improve ovule culture for the recovery of plants from immature embryos, we present results in this report about various media, type of ovule support, orientation, and culture vessel type.

\section{Materials \& Methods}

Expt. 1. Genotype and media effects on embryo development in cultured ovules and subsequent germination of cultured embryos. Fruit was harvested from nine peach and nectarine families from 55 to $70 \mathrm{~d}$ after bloom (DAB) (Table 1). After the stems had been removed, fruit was surface sterilized by agitating in $70 \%$ ethanol for $1 \mathrm{~min}$, washing in $0.525 \%$ sodium hypochlorite containing $0.01 \%$ Tween 20 for $10 \mathrm{~min}$ and rinsing with sterile distilled water. The fruit were cut open in a laminar flow hood with double bladed clippers dipped in $70 \%$ ethanol. Ovules were extracted, using aseptic techniques, and ten were placed within each cylindrical polycarbonate jar $(95 \times 65 \mathrm{~mm})$ containing $30 \mathrm{~mL}$ of liquid medium with a 7-cm diameter \#541 Whatman filter paper support (FPS), (Stewart and Hsu, 1978) or $30 \mathrm{~mL}$ of agar-gelled medium. Each jar was sealed with a screw top lid. The headspace volume, with the addition of the liquid or agar medium in the polycarbonate jar container, was $28.2 \mathrm{~cm}^{3} /$ ovule. The media treatments were as follows: 1) Stewart and Hsu medium (SH) (Stewart and Hsu, 1978), 6\% sucrose, FPS; 2) $\mathrm{SH}, 6 \%$ sucrose, $0.3 \%$ activated charcoal (AC), FPS; 3) SH, 6\% sucrose, $0.65 \%$ agar; 4) $\mathrm{SH}, 6 \%$ sucrose, $0.3 \% \mathrm{AC}, 0.65 \%$ agar; 5) SH, 10\% sucrose, FPS; and 6) Quoirin and Lepoivre (1977) medium (QL), 6\% sucrose, FPS. The $\mathrm{pH}$ was adjusted to 5.7 with $1 \mathrm{~N}$ $\mathrm{HC} 1$ or $1 \mathrm{~N} \mathrm{NaOH}$. The funicular side of each ovule was pushed into the agar-gelled medium. One jar containing 10 ovules was cultured for each family and treatment, for a total of 60 ovules per family or 90 ovules per treatment. In addition, 10 embryos from each family were removed from ovules at the initiation of the experiment and their lengths recorded to determine an average initial embryo length for each family.

Embryos were removed from the ovules after incubation in the dark at $27^{\circ} \mathrm{C}$ for 24 to $33 \mathrm{~d}$ and their lengths and weights recorded. Embryos were then transferred to test tubes $(20 \times 150 \mathrm{~mm})$, containing $10 \mathrm{~mL}$ of Woody Plant medium (WP) (Lloyd and McCown, 1981) gelled with $0.65 \%$ agar plus $3 \%$ sucrose. Test tube closures were Permeable Membrane (PM) caps (Biomedical Polymers, Leominster, Mass.). Ovules cultured on agar-gelled media required soaking in sterile distilled water overnight to soften the testa and facilitate embryo removal. All embryos were pushed, radicle end down, halfway into the medium. Stratification for $60 \mathrm{~d}$ at $1.5^{\circ} \mathrm{C}$ began immediately after transfer. After stratification, embryos were placed in a plant growth chamber at $20{ }^{\circ} \mathrm{C}$ under cool-white fluorescent lights with a 12-h photoperiod. Light intensity was $\approx 36.5 \mu \mathrm{mol} \cdot \mathrm{m}^{-2} \cdot \mathrm{s}^{-1}$. After 1 week, embryos were transferred to a growth room at $25{ }^{\circ} \mathrm{C}$ under cool-white fluorescent lights with a 12 -h photoperiod. Light energy was $\approx 58.4$ $\mu \mathrm{mol} \cdot \mathrm{m}^{-2} \cdot \mathrm{s}^{-1}$. Germination was recorded 3 weeks later. Fresh weights for each germinated seedling and its associated pair of cotyledons were recorded separately (Table 2).

An analysis of variance (ANOVA) was performed on data using Systat MGLH/GLM program (Wilkinson, 1989). Where significance of independent variables and their interactions occurred, a two-way ANOVA was performed along with a Tukey's honestly significantly different (HSD) multiple comparison test on pairs of means, developing a matrix of pairwise comparison probabilities.

Expt. 2. Effect of culture vessel and ovule 
orientation on embryo development in cultured ovules and subsequent germination of cultured embryos. Open pollinated fruit from two nectarine families (K626-90 and P30-129) were harvested 67 DAB. Embryos were extracted from a representative sample and their embryo lengths recorded (Table 1). The remaining fruit were surface sterilized and cracked open as in Expt. 1. Ovules were aseptically removed and placed either into petri dishes $(25 \times 100 \mathrm{~mm})$, each containing $30 \mathrm{~mL}$ of $\mathrm{SH}$ medium with $6 \%$ sucrose, $0.65 \%$ agar, $5 \mathrm{~mm} 2$ - $(N$-morpho lino)ethanesulfonic acid (MES) or test tubes $(20 \times 150 \mathrm{~mm})$ each containing $3 \mathrm{~mL}$ of the same medium. The headspace volumes in the petri dishes and test tubes were $15.7 \mathrm{~cm}^{3} /$ ovule and $42.4 \mathrm{~cm}^{3} /$ ovule, respectively. The medium volume placed within a test tube was equivalent to the average amount of medium available for each ovule in a petri dish (total medium volume/ number of ovules). The $\mathrm{pH}$ was adjusted to 6.0 with $1 \mathrm{~N} \mathrm{HC1}$ or $\mathrm{NaOH}$. Ten ovules were placed within each petri dish and replicated four times for each treatment. The test tube treatment was replicated 40 times. Ovules were placed in four different orientations: 1) petri dish with ovule placed funiculus side into agar/horizontal orientation $(\mathrm{PDFD} / \mathrm{H}) ; 2$ ) petri dish with ovule placed funiculus side up/horizontal orientation $(\mathrm{PDFU} / \mathrm{H})$ (rotated $180^{\circ}$ from treatment 1$)$; 3) petri dish with ovule placed micropylar end into agar/vertical orientation (PDMD/V); 4) Test tube with ovule placed micropylar end into agar/vertical orientation (TTMD/V). Ovules in all the above treatments were pushed into agar half their length or width (except for treatment $\mathrm{PDMD} / \mathrm{V}$, which was one-fourth its length). Ovules in the above treatments were placed into a dark incubator at $27^{\circ} \mathrm{C}$ for $30 \mathrm{~d}$. Embryos were aseptically removed from cultured ovules after $30 \mathrm{~d}$ of incubation and their lengths and weights recorded. Embryos were transferred to test tubes containing $10 \mathrm{~mL}$ WP medium, $3 \%$ sucrose, $0.65 \%$ agar, 5 mM MES with a pH of 6.0. These test tubes were placed for $45 \mathrm{~d}$ into a dark cooler at $1.5^{\circ} \mathrm{C}$. The embryos were allowed to germinate, after chilling, inside a growth chamber at $20{ }^{\circ} \mathrm{C}$ under cool-white fluorescent lights (light intensity $\approx 36.5 \mu \mathrm{mol} \cdot \mathrm{m}^{-2} \cdot \mathrm{s}^{-1}$ ), with a 12-h photoperiod. Germination was rated 2 weeks later. Embryos were considered to have germinated when the radicle was equal to or greater than half the length of its cotyledons. After 5 weeks, plants were taken out of test tubes, cotyledons removed and plant weights recorded. Plants were then transplanted to soil and survival was recorded.

Expt. 3. Effect of culture vessel and ovule orientation on embryo development in cultured ovules and subsequent germination of cultured embryos. Open pollinated fruit from two nectarine families (P29-80 and P59-29) were harvested 56 and $63 \mathrm{DAB}$, respectively. Embryos were extracted from a representative sample and their embryo lengths recorded. The remaining fruit were surface sterilized and ovules aseptically removed as previously described. Ovules were placed either into petri dishes $(25 \times 100 \mathrm{~mm})$, cylindrical polycarbonate jars $(65 \times 95 \mathrm{~mm})$ each containing $30 \mathrm{~mL}$ of SH medium, $6 \%$ sucrose, $5 \mathrm{~mm}$ MES and $0.65 \%$ agar or test tubes $(20 \times 150 \mathrm{~mm})$ each containing $3 \mathrm{~mL}$ of the same medium. Ten ovules were placed within each petri dish or polycarbonate jar and replicated four times for each treatment. The test tube treatment was replicated 40 times. Ovules were placed in four treatments: 1) test tube cultured with micropylar end pushed into agar/vertical orientation;(TTMD/V);2) petri dish with funiculus side pushed into agar/horizontal orientation (PDFD/H);3) polycarbonate jar with funiculus side pushed into agar/horizontal orientation (PJFD/H); 4) polycarbonate jar with micropylar end pushed into agar/vertical orientation (PJMD/V). Ovules, in all the above treatments, were pushed into the agar half their length or width. The above treatments were placed into a dark incubator at $27^{\circ} \mathrm{C}$ for $30 \mathrm{~d}$. Embryos, after $30 \mathrm{~d}$ of incubation, were aseptically removed from ovules and their weights recorded (Table 4). Embryos were then transferred to test tubes containing $10 \mathrm{~mL}$ WP medium, $3 \%$ sucrose, $0.65 \%$ agar, and 5 mM MES. These test tubes were placed for $60 \mathrm{~d}$ into a dark cooler at $1.5{ }^{\circ} \mathrm{C}$. After $60 \mathrm{~d}$, embryos were placed inside a growth chamber at $20{ }^{\circ} \mathrm{C}$, under cool-white fluorescent lights (light intensity $\approx 36.5 \mu \mathrm{mol} \cdot \mathrm{m}^{-2} \cdot \mathrm{s}^{-1}$ ) with a 12 -h photoperiod. Germination was rated $18 \mathrm{~d}$ later. After an additional week, plants were taken out of test tubes, cotyledons removed and plant weights recorded (Table 4).

In Expts. 2 and 3, ANOVA was performed on data using the general linear modeling program in Super ANOVA (Abacus Concepts, Berkeley, Calif.). Where significance of independent variables occurred, a two-way ANOVA was performed along with a Tukey's HSD multiple comparison test on pairs of means, developing a matrix of pairwise comparison probabilities.

\section{Results}

Expt. 1. Genotype and media effects on embryo development in cultured ovules and subsequent germination of cultured embryos. The embryos enlarged during ovule culture for all nine families. There was significant difference among families for embryo enlargement during ovule culture. Families 8 and 9 had significantly greater embryo lengths than any other family with a $48 \%$ and $56 \%$ increase over initial embryo length, respectively. Families 1,2 , and 7 had the smallest embryo length after $\approx 1$ month of ovule culture and were not significantly different from each other, but had increased over initial embryo length by $\approx 5 \mathrm{~mm}$. Families with smaller initial embryo lengths ( 0.5 to $1.5 \mathrm{~mm}$ initial size range) had a greater percent increase in length than those within the 3 to $6 \mathrm{~mm}$ initial size range (Tables 1 and 2). The correlation of initial embryo length with embryo length and embryo FW after the ovule culture period was $r=0.90$ (Sig. Probability $=$ 0.0008 ) and 0.75 (Sig. Probability $=0.0197$ ) respectively, supporting the above observation. Families 5, 6, and 8 had the greatest embryo weight after $\approx 30 \mathrm{~d}$ of ovule culture (Table 2 ). The germination rate was comparable $(30 \%$ to $55 \%$ ) for all families even though their initial embryo lengths ranged from 0.6 to 6.2 $\mathrm{mm}$. The correlation of initial embryo length with the percentage of germination and the percentage of plants per embryos was $r=$ -0.63 (Sig. Probability $=0.0689$ ) and -0.31 $($ Sig. Probability $=0.4155)$, respectively, corresponding to the above observations. Family 4 had the smallest initial embryo length but the highest germination rate (Tables 1 and 2). The size of plants large enough to be transplanted to soil was also similar across the different families. However, family 7 was the poorest for all measurements made except for average cotyledon weight.

There were no significant interactions between families and treatments for embryo length, weight, and cotyledon weight. The length and weight of the extracted embryos from all the tested families were significantly larger when ovules were cultured on agar treatments (SH6SA and SH6SACA). Treatments SH6SA and SH6SACA were significantly different from each other with AC (treatment SH6SACA) having greater embryo length and weight. Embryos from ovules incubated on liquid media treatments (SH6SFPS, SH6SACFPS, SH10SFPS and QL6SFPS) did not enlarge sufficiently for many to be transplanted to soil. However, both agar treatments (SH6SA and SH6SACA) induced embryo development into plants large enough such that $>90 \%$ could be transplanted to soil.

Expt. 2. Effect of culture vessel and ovule orientation on embryo development in cultured ovules and subsequent germination of cultured embryos. The embryos of the family P30-129 grew larger (length and weight) and produced more plants, even though the initial embryo length was smaller than that of K62690 (Tables 1 and 3). Once transplanted to soil, the percentage of plant survival was similar for both families. Embryos from 30-d-old cultured ovules (6.3 to $8.9 \mathrm{~mm}$ length, 109 to $183 \mathrm{mg}$ weight) were less than half the size of embryos from tree grown ovules the same age (12.4 to $14.9 \mathrm{~mm}$ length, 316 to $454 \mathrm{mg}$ weight) (Tables 1 and 3). The various ovule orientation treatments within the two types of culture vessels resulted in similar embryo weights. In treatment $\mathrm{PDMD} / \mathrm{V}$, embryo length and weight values were consistently lower (Table 3 ). Although embryo germination was similar for the various treatments, plant weight in the TTMD/V treatment was significantly greater than the rest. When excised after stratification, more embryos from this treatment had a pearly white healthy appearance, resulting in the greatest plant survival (Table 3 ).

Expt. 3. Effect of culture vessel and ovule orientation on embryo development in cultured ovules and subsequent germination of cultured embryos. The two families under investigation differed for all recorded growth variables (Table 4). P52-29 had significantly greater embryo and plant weight, whereas P2980 had significantly greater germination and percent of plants surviving (Table 4). Treatment TTMD/V had significantly larger embryos after the ovule culture period. Treatment PDFD/ H consistently had the lowest values for all growth 
Table 1. Parentage of families, culture date, initial embryo length and duration of culture period for experiments on embryo culture of Prunus.

\begin{tabular}{|c|c|c|c|c|c|c|c|c|c|c|}
\hline \multirow[b]{2}{*}{ Family } & \multicolumn{2}{|c|}{ Parentage } & \multirow{2}{*}{$\begin{array}{l}\begin{array}{l}\text { Fruit } \\
\text { type }\end{array} \\
\end{array}$} & \multirow{2}{*}{$\begin{array}{c}\text { Bloom } \\
\text { date }\end{array}$} & \multirow{2}{*}{$\begin{array}{c}\text { Collection } \\
\text { date }\end{array}$} & \multirow{2}{*}{$\begin{array}{c}\text { Days after } \\
\text { pollination }\end{array}$} & \multirow{2}{*}{$\begin{array}{c}\text { Avg init emb } \\
\text { len }(\mathrm{mm})\end{array}$} & \multirow{2}{*}{$\begin{array}{l}\text { Days in } \\
\text { culture }\end{array}$} & \multicolumn{2}{|c|}{ After 1 month on tree } \\
\hline & Female & Male & & & & & & & Avg emb len (mm) & Avg emb wt (mg) \\
\hline & & & & & & Expt. 1 & & & & \\
\hline 1 & P78-21 & P30-129 & $\mathrm{NE}^{\mathrm{z}}$ & 3/1/1994 & 4/25/1994 & 55 & 1.0 & 24 & & \\
\hline 3 & P78-21 & K622-3 & $\mathrm{NE}$ & $3 / 1 / 1994$ & $4 / 25 / 1994$ & 55 & 1.3 & 27 & & \\
\hline 4 & P45-141 & P45-11 & PE & $3 / 1 / 1994$ & 4/25/1994 & 55 & 0.6 & 27 & & \\
\hline 5 & K622-3 & P97-14 & $\mathrm{NE}$ & $3 / 2 / 1994$ & $5 / 6 / 1994$ & 65 & 3.4 & 29 & & \\
\hline 6 & K622-3 & P36-1 & $\mathrm{NE}$ & 3/3/1994 & $5 / 6 / 1994$ & 64 & 3.1 & 29 & & \\
\hline \multirow[t]{6}{*}{9} & P45-142 & P46-36 & PE & 3/4/1994 & $5 / 13 / 1994$ & 70 & 5.6 & 30 & & \\
\hline & & & & & & Expt. 2 & & & & \\
\hline & K626-90 & $\mathrm{OP}^{\mathrm{y}}$ & $\mathrm{NE}$ & $2 / 19 / 1995$ & 4/27/1995 & 67 & 1.0 & 30 & 14.9 & 454 \\
\hline & P30-129 & OP & $\mathrm{NE}$ & $2 / 19 / 1995$ & 4/27/1995 & 67 & 0.6 & 30 & 12.4 & 316 \\
\hline & & & & & & Expt. 3 & & & & \\
\hline & P29-80 & OP & $\mathrm{NE}$ & $3 / 5 / 1996$ & 4/30/1996 & 56 & 1.8 & 30 & & \\
\hline
\end{tabular}

${ }^{2} \mathrm{NE} / \mathrm{PE}=$ nectarine/peach.

${ }^{\mathrm{y}} \mathrm{OP}=$ open pollinated.

Table 2. Embryo size, germination, and plant growth for embryo culture of nine families of Prunus after ovules had been cultured on any of six media treatments in Expt. 1.

\begin{tabular}{lccccccc}
\hline Family & $\begin{array}{c}\text { Avg EL }^{z} \\
(\mathrm{~mm})\end{array}$ & $\begin{array}{c}\text { Avg EL } \\
\text { inc (\%) }\end{array}$ & $\begin{array}{c}\text { Avg EW } \\
(\mathrm{mg})\end{array}$ & $\begin{array}{c}\text { Germ } \\
(\%)\end{array}$ & $\begin{array}{c}\text { Avg cot wt } \\
(\mathrm{mg})\end{array}$ & $\begin{array}{c}\text { Avg plt wt } \\
(\mathrm{mg})\end{array}$ & $\begin{array}{c}\text { Plts/\# embs } \\
(\%)\end{array}$ \\
\hline 1 & $6.0 \mathrm{ab}^{\mathrm{s}}$ & 478 & $65 \mathrm{a}$ & $35 \mathrm{ab}$ & $374 \mathrm{a}$ & $484 \mathrm{a}$ & 34 \\
2 & $6.3 \mathrm{abc}$ & 346 & $66 \mathrm{a}$ & $42 \mathrm{bc}$ & $288 \mathrm{a}$ & $385 \mathrm{a}$ & 42 \\
3 & $7.0 \mathrm{cde}$ & 435 & $87 \mathrm{ab}$ & $50 \mathrm{c}$ & $321 \mathrm{a}$ & $499 \mathrm{a}$ & 40 \\
4 & $6.6 \mathrm{bcd}$ & 1104 & $104 \mathrm{abc}$ & $55 \mathrm{c}$ & $386 \mathrm{ab}$ & $442 \mathrm{a}$ & 32 \\
5 & $7.7 \mathrm{e}$ & 129 & $126 \mathrm{~cd}$ & $34 \mathrm{ab}$ & $569 \mathrm{c}$ & $356 \mathrm{a}$ & 33 \\
6 & $7.3 \mathrm{de}$ & 139 & $126 \mathrm{~cd}$ & $31 \mathrm{ab}$ & $565 \mathrm{c}$ & $369 \mathrm{a}$ & 31 \\
7 & $5.6 \mathrm{a}$ & 201 & $63 \mathrm{a}$ & $30 \mathrm{a}$ & $327 \mathrm{a}$ & $352 \mathrm{a}$ & 25 \\
8 & $9.1 \mathrm{f}$ & 48 & $157 \mathrm{~d}$ & $31 \mathrm{ab}$ & $655 \mathrm{c}$ & $404 \mathrm{a}$ & 31 \\
9 & $8.7 \mathrm{f}$ & 56 & $110 \mathrm{bc}$ & $32 \mathrm{ab}$ & $530 \mathrm{bc}$ & $460 \mathrm{a}$ & 32 \\
Treatment & & & & & & & \\
SH6SFPS & $5.0 \mathrm{a}$ & 85 & $22 \mathrm{a}$ & $3 \mathrm{a}$ & $*$ & $*$ & 0 \\
SH6SACFPS & $5.7 \mathrm{~b}$ & 111 & $25 \mathrm{a}$ & $16 \mathrm{c}$ & $124 \mathrm{a}$ & $305 \mathrm{a}$ & 12 \\
SH6SA & $10.6 \mathrm{c}$ & 293 & $208 \mathrm{~b}$ & $94 \mathrm{~d}$ & $395 \mathrm{~b}$ & $436 \mathrm{a}$ & 93 \\
SH6SACA & $11.7 \mathrm{~d}$ & 333 & $282 \mathrm{c}$ & $92 \mathrm{~d}$ & $536 \mathrm{~b}$ & $422 \mathrm{a}$ & 90 \\
SH10SFPS & $5.4 \mathrm{ab}$ & 100 & $24 \mathrm{a}$ & $4 \mathrm{ab}$ & $94 \mathrm{a}$ & $227 \mathrm{a}$ & 2 \\
QL6SFPS & $5.8 \mathrm{~b}$ & 115 & $37 \mathrm{a}$ & $13 \mathrm{bc}$ & $279 \mathrm{ab}$ & $534 \mathrm{a}$ & 1 \\
\hline
\end{tabular}

${ }^{\mathrm{z}} \mathrm{Avg}$ EL $=$ average embryo length after 24 to $33 \mathrm{~d}$ of ovule culture.

y\% Inc avg EL = percent increase in average embryo length during ovule culture.

${ }^{\mathrm{x}} \mathrm{Avg} \mathrm{EW}=$ average embryo weight after 24 to $33 \mathrm{~d}$ of ovule culture.

w\% Germ = percent germination, 3 weeks after stratification.

${ }^{\mathrm{v}} \mathrm{Avg} \cot \mathrm{wt}=$ average cotyledon weight, 3 weeks after stratification.

"Avg plt wt $=$ average plant weight, 3 weeks after stratification.

t\% Plts/\# embs = percent plants per number of embryos cultured

$\mathrm{s}=$ means with the same letter are not significantly different $(\mathrm{N}=60$ by family, 90 by treat. $)(P=0.05)$ using Tukey's HSD multiples comparison test.

'Treatments: SH6SFPS = Stewart and Hsu, 6\% sucrose, filter paper support; SH6SACFPS = Stewart and Hsu, 6\% sucrose, activated charcoal filter paper support; SH6SA = Stewart and Hsu, 6\% sucrose, agar; SH6SACA = Stewart and Hsu, 6\% sucrose, activated charcoal, agar; SH10SFPS = Stewart and Hsu, $10 \%$ sucrose, filter paper support; QL6SFPS = Quoirin and Lepoive, 6\% sucrose, filter paper support.

parameters measured. The test tube and polycarbonate jar treatments with the micropyle down produced the largest embryos and plants for all growth variables measured.

\section{Discussion}

Expt. 1. Genotype and media effects on embryo development in cultured ovules and subsequent germination of cultured embryos. Only polycarbonate jars with screw top lids were used for all treatments. The two best treatments (SH6SA and SH6SACA) had agar for support. Ovules placed on their sides on FPS allowed only a small surface area to come in contact with the medium. This may have inhibited media uptake resulting in poor embryo development. Embryos excised from these treatments showed uneven cotyledon development. The cotyledon that had been against the filter paper was always larger. Pinto et al. (1994) working with Prunus showed that ovule orientation or positioning greatly influenced embryo development. When comparing vertically to horizontally grown ovules, vertical orientation had greater embryo weights. Santarem et al. (1997) and McClelland and Smith (1990) have shown that explant orientation in vitro influences its response to its surroundings. Agar medium allows the nutrients to be exposed to both cotyledons. The use of agar as a support is much easier and quicker to prepare, and allows earlier detection of contamination. As was previously reported (Emershad and
Ramming, 1994) the in ovulo cultured embryos within the 0.5 - to $1.5-\mathrm{mm}$ initial size range responded more favorably than the 3- to 6-mm initial size range.

When AC was added to the SH6S media containing agar (SH6SACA), significantly larger embryo development was achieved. The role AC made in this difference may have been to increase post autoclave $\mathrm{pH}$ as well as absorbing inhibitory compounds such as polyphenols (Owen et al., 1991).

Expt. 2. Effect of culture vessel and ovule orientation on embryo development in cultured ovules and subsequent germination of cultured embryos. The shallow ovule depth in the petri dish with the micropyle down (treatment $\mathrm{PDMD} / \mathrm{V}$ ) resulted in reduced embryo length and weight. The test tube (treatment TTMD/V) with its vertical ovule orientation (micropyle end down) and greater headspace resulted in proper embryo development and appearance. The test tube closure may have also permitted more aeration than the parafilm wrap on the petri dishes. Researchers studying explant orientation, vessel size, aeration and gases within in vitro environments found all have an effect upon growth. Pinto et al. (1994) working with peach ovules found vertical placement of explant was more beneficial than media or sugar level. Laforge et al. (1990) mentions the gas diffusion rate into a vessel is a function of the type of closure. Since closures were different, the gas diffusion rates may have been different in our study. Demeester et al. (1995) found that growth declines in a more tightly closed container, and that the closure's gas exchange mechanism affected the vessels headspace composition. Auboiron et al. (1990) found that Hevea calli growing in confined conditions, produced large amounts of carbon dioxide and ethylene gases. Over time, excessive levels of these gases were shown to be inhibitory to callus growth and somatic embryo induction. Adkins et al. (1998) found that medium additives to control excessive levels of ethylene would benefit coconut and papaya callus growth, somatic embryo proliferation, maturation and germination. The smaller embryo size after $30 \mathrm{~d}$ of in vitro 
Table 3. Embryo size, germination, plant growth, and survival for embryo cultures of two families after ovules had been cultured in four treatments in Expt. 2.

\begin{tabular}{|c|c|c|c|c|c|c|}
\hline Family & $\begin{array}{c}\text { Avg emb len } \\
(\mathrm{mm})\end{array}$ & $\begin{array}{l}\text { Avg emb wt }{ }^{y} \\
(\mathrm{mg})\end{array}$ & $\begin{array}{c}\text { Germ }^{x} \\
(\%)\end{array}$ & $\begin{array}{l}\text { Avg Plt wt } \mathrm{t}^{\mathrm{w}} \\
(\mathrm{mg})\end{array}$ & $\begin{array}{l}\text { Plts }^{v} \\
(\%)\end{array}$ & $\begin{array}{c}\text { Plt surv }{ }^{\mathrm{u}} \\
\%\end{array}$ \\
\hline K626-90 & $6.3 \mathrm{a}^{\mathrm{t}}$ & $109 \mathrm{a}$ & $94 \mathrm{a}$ & $265 \mathrm{a}$ & $16 \mathrm{a}$ & $83 \mathrm{a}$ \\
\hline P30-129 & $8.9 \mathrm{~b}$ & $183 \mathrm{~b}$ & $99 \mathrm{a}$ & $279 a$ & $68 \mathrm{~b}$ & $81 \mathrm{a}$ \\
\hline \multicolumn{7}{|l|}{ Treatment ${ }^{\mathrm{s}}$} \\
\hline $\mathrm{PDFD} / \mathrm{H}$ & $9.0 \mathrm{~b}$ & $178 \mathrm{a}$ & $100 \mathrm{a}$ & $225 \mathrm{a}$ & $23 \mathrm{a}$ & $71 \mathrm{a}^{\mathrm{r}}$ \\
\hline $\mathrm{PDFU} / \mathrm{H}$ & $9.0 \mathrm{~b}$ & $179 \mathrm{a}$ & $100 \mathrm{a}$ & $231 \mathrm{a}$ & $49 \mathrm{bc}$ & $75 \mathrm{ab}$ \\
\hline PDMD/V & $7.9 \mathrm{a}$ & $159 a$ & $90 \mathrm{a}$ & $236 \mathrm{a}$ & $42 b$ & $81 \mathrm{ab}$ \\
\hline TTMD/V & $8.4 \mathrm{ab}$ & $174 \mathrm{a}$ & $100 \mathrm{a}$ & $356 \mathrm{~b}$ & $60 \mathrm{c}$ & $89 \mathrm{~b}$ \\
\hline
\end{tabular}

${ }^{\mathrm{z}} \mathrm{Avg}$ emb len = average embryo length after $30 \mathrm{~d}$ of ovule culture.

${ }^{y} \mathrm{Avg}$ emb wt $=$ average embryo weight after $30 \mathrm{~d}$ of ovule culture.

$x \%$ Germ $=$ percent germination in test tube, 2 weeks after stratification.

${ }^{\mathrm{w}}$ Avg plt wt $=$ average plant weight, 5 weeks after stratification.

$\checkmark \%$ Plts $=$ percent plants/10 ovules, 5 weeks after stratification.

ч\% Plt surv = percent plant survival after establishment in soil.

${ }^{t}$ Means with the same letter are not significantly different $(\mathrm{N}=40)(P=0.05)$ using Tukey's HSD multiple comparison test.

${ }^{s}$ Treatments $=$ PDFDA/H: petri dish with funiculus down, agar/horizontal orientation; $\mathrm{PDFU} / \mathrm{H}$ : petri dish with funiculus up, agar/horizontal orientation; PDMD/V: petri dish with micropyle down, agar/ vertical orientation; TTMD/V: test tube with micropyle down, agar/vertical

orientation.

${ }^{\mathrm{r}}$ Means with the same letter are not significantly different $(P=0.1)$ using Fisher's Protected LSD.

Table 4. Embryo size, germination, plant growth and percent plants after embryo culture of two families and four ovule treatments in Expt. 3.

\begin{tabular}{lcccc}
\hline Family & Avg emb wt $^{\mathrm{z}}(\mathrm{mg})$ & ${\text { Germ }(\%)^{\mathrm{y}}}$ & Avg Plt wt $^{\mathrm{x}}(\mathrm{mg})$ & Plts $^{\mathrm{w}}(\%)$ \\
\hline P29-80 & $126 \mathrm{a}^{\mathrm{v}}$ & $90 \mathrm{~b}$ & $902 \mathrm{a}$ & $90 \mathrm{~b}$ \\
P-52-59 & $198 \mathrm{~b}$ & $80 \mathrm{a}$ & $1050 \mathrm{~b}$ & $75 \mathrm{a}$ \\
Treatment $^{\mathrm{u}}$ & & & & \\
TTMD/V & $184 \mathrm{c}$ & $90 \mathrm{~b}$ & $1062 \mathrm{~b}^{\mathrm{t}}$ & $91 \mathrm{~b}$ \\
PDFD/H & $125 \mathrm{a}$ & $70 \mathrm{a}$ & $842 \mathrm{a}$ & $61 \mathrm{a}$ \\
PJFD/H & $151 \mathrm{ab}$ & $90 \mathrm{~b}$ & $902 \mathrm{a}$ & $91 \mathrm{~b}$ \\
PJMD/V & $162 \mathrm{~b}$ & $90 \mathrm{~b}$ & $1024 \mathrm{~b}$ & $88 \mathrm{~b}$ \\
\hline
\end{tabular}

${ }^{\mathrm{z}} \mathrm{Avg}$ emb $\mathrm{wt}=$ average embryo weight after $30 \mathrm{~d}$ of ovule culture.

y $\%$ Germ = percent germination, $18 \mathrm{~d}$ after stratification.

${ }^{\mathrm{x}} \mathrm{Avg}$ plt wt $=$ average plant weight, $25 \mathrm{~d}$ after stratification.

$\mathrm{w} \%$ Plts $=$ percent plants $/ 10$ ovules.

${ }^{v}$ Means with the same letter are not significantly different $(\mathrm{N}=40)(P=0.05)$ using

Tukey's HSD multiple comparison test

"Treatments =TTMD/V: test tube culture with micropyle end in agar/vertical; $\mathrm{PDFU} / \mathrm{H}$ : petri dish culture with funiculus side down into agar/horizontal; PJFD/H: polycarbonate jar with funiculus side down into agar/horizontal; PJMD/V: polycarbonate jar with micropyle end down into agar/vertical.

'Means with the same letter are not significantly different $(P=0.1)$ using Fisher's Protected LSD test

culture compared to in vivo growth (Table 1) demonstrates that all growth requirements for full embryo development are not being met.

Expt. 3. Effect of culture vessel and ovule orientation on embryo development in cultured ovules and subsequent germination of cultured embryos. Test tubes and polycarbonate jars containing ovules with vertical orientation with the micropylar end into agar produced the largest embryos and plants (Table 4) compared with horizontal ovule orientation. The horizontal orientation may affect embryo development by minimizing exposure to nutrients. In addition, the poorer embryo growth within petri dishes could be attributed to a reduced headspace volume and sealing with parafilm which would reduce aeration, thereby modifying headspace gas composition within the dish. The number of explants within different size vessels can affect growth, by increasing metabolic byproducts, which, if not properly dissipated could inhibit growth. Many researchers have reported on vessel size and headspace gas composition and how it affects plant growth. Monette (1983) and McClelland and Smith (1990) studying shoot tip cultures of various species found that as the vessel size becomes larger, shoot tip proliferation increased. In addition, McClelland and Smith (1990) observed that if vessels were not sealed with parafilm that shoot quality was better. It was suggested that this may be due to better gas exchange within the vessel. Auboiron et al. (1990), Laforge et al. (1990) and Demeester et al. (1995) have shown that the size of the culture container and the closure device determine the headspace gas composition which influences growth of the plant material. Laforge et al. (1990) found that growth could be slightly enhanced in plantlets of asparagus and strawberries by proper gas exchange in miniature growth chambers. Auboiron et al. (1990) working with Hevea showed by avoiding the accumulation of excessive levels of gases such as ethylene and carbon dioxide, that somatic embryo induction would not be inhibited. It has been shown that vessels that differ in their gas exchange mechanism affect headspace composition. Demeester et al. (1995) working with Prunus shoot tips observed that as gas exchange slows down due to a more tightly closed container, the growth rate declined accordingly.

\section{Conclusion}

In our studies, test tubes and polycarbonate containers used in conjunction with agar were beneficial to ovule/embryo development. Agar permitted the proper positioning of the ovule increasing its surface area of contact allowing for more nutrient uptake. Test tubes and polycarbonate containers allowed for more media depth to permit proper ovule insertion and had greater headspace volume for possibly better gas composition than petri dishes. Perhaps to further improve Prunus embryo growth within the ovule, one could increase gas exchange within the culture vessel. Studies of interest would be comparing different vessel closures to increase gas exchange yet minimize water loss. To prevent the spread of contamination and eliminate explant interaction of in ovulo embryo cultures, one may use test tubes over polycarbonate jars. With the proper medium, support, vessel and closure, in ovulo embryo culture of Prunus can be enhanced. These findings, if utilized in Prunus breeding programs, should generate greater numbers of hybrid progenies accelerating the development of early-ripening selections and cultivars.

\section{Literature Cited}

Adkins, S.W., Y.M. Samosir, A. Ernawati, I.D. Godwin and R.A. Drew. 1998. Control of ethylene and use of polyamines can optimise the conditions for somatic embryogenesis in coconut (Cocos nucifera L.) and papaya (Carica papaya L.). In: R.A. Drew (ed.). Proc. Int. Symp. Biotech. Trop. and Subtrop. Species. Acta. Hort. 461, Intl. Soc. Hort.Sci.

Auboiron, E., M-P. Carron and N. Michaux-Ferrière. 1990. Influence of atmospheric gases, particularly ethylene, on somatic embryogenesis of Hevea brasiliensis. Plant Cell Tiss. Org. Cult. 21:31-37.

Blake, M.A. 1939. Some results of crosses of early ripening varieties of peaches. Proc. Amer. Soc. Hort. Sci. 37:232-241.

Demeester, J.J., D.G. Matthijs, B. Pascat, and P.C. Debergh. 1995. Toward a controllable headspace composition-Growth, development, and headspace of a micropropagated Prunus rootstock in different containers. In Vitro Cell. Dev. Biol. 31:105-112.

Emershad, R.L. and D.W. Ramming. 1994. Effects of media on embryo enlargement, germination and plant development in early-ripening families of Prunus grown in vitro. Plant Cell Tiss. Org. Cult. 37:55-59.

Laforge, F., Y. Desjardins, M.E.D. Graham, and A. Gosselin. 1990. Miniature growth chambers for the study of environmental conditions in vitro. Can. J. Plant Sci. 70:825-836.

Lloyd, G. and B. McCown. 1981. Commercially-feasible microprogation of mountain laurel, Kalmia latifolia, by use of shoot-tip culture. Comb. Proc. Intl. Plant Prop. Soc. 30: 421-427.

McClelland, M.T. and M.A.L. Smith. 1990. Vessel type, closure and explant orientation influence in vitro performance of five woody species. HortScience 25:797-800.

Monette, P.L. 1983. Influence of size of culture vessel on in vitro proliferation of grape in a liquid medium. Plant Cell Tiss. Org. Cult. 2: 327-332.

Murashige,T. and F. Skoog. 1962. Arevised medium for rapid growth and bioassays with tobacco tissue cultures. Physiol. Plant. 15:473-497. 


\section{Breeding, Cultivars, Rootstocks, \& Germplasm Resources}

Owen, H.R., D. Wengerd, and A.R. Miller. 1991. Culture medium $\mathrm{pH}$ is influenced by basal medium, carbohydrate source, gelling agent, activated charcoal, and medium storage method. Plant Cell Rep. 10:583-586.

Pinto, A.C.Q., S.M. Dethier Rogers, and D.H. Byrne. 1994. Growth of immature peach embryos in response to media, ovule support method and ovule perforation. HortScience 29:1081-1083.

Quoirin, M. and P. Lepoivre. 1977. Improved media for in vitro culture of Prunus. Acta. Hort. 78: 437-442.

Ramming, D.W. 1985. In ovulo embryo culture of early-ripening Prunus. HortScience 20: 419-420.

Ramming, D.W. 1990. The use of embryo culture in fruit breeding. HortScience 25:393-398.

Santarem, E.R., B. Pelissier, and J.J. Finer. 1997. Effect of explant orientation, $\mathrm{pH}$, solidifying agent and wounding on initiation of soybean somatic embryos. In Vitro Cell. Dev. Biol.-Plant 33:13-19.

Smith, C.A., C.H. Bailey, and L.F. Hough. 1969. Methods for germinating seeds of some fruit species with special reference to growing seedlings from immature embryos. New Jersey Agr.
Expt. Sta. Bul. 823.

Stewart, J. McD. and C.L. Hsu. 1977. In-ovulo embryo culture and seedling development of cotton (Gossypium hirsutum L.). Planta 137: 113-117.

Stewart, J. McD. and C.L. Hsu. 1978. Hybridization of diploid and tetraploid cottons through in-ovulo embryo culture. J. Hered. 69:404-408.

Tukey, H.B. 1934. Artificial culture methods for isolated embryos of deciduous fruits. Proc. Amer. Soc. Hort. Sci. 32:313-322.

Wilkinson, L. 1989. SYSTAT: The system for statistics. SYSTAT, Evanston, Ill. 